\title{
O futebol no Vale do São Francisco: os significados do torneio BAPE em Juazeiro-BA e Petrolina-PE
}

\author{
Francisco Demetrius Luciano Caldas ${ }^{\mathrm{a}, *}$, Alvaro Rego Millen Neto ${ }^{b}$, Bruno Otávio de Lacerda Abrahão ${ }^{c}$
}

\section{Palavras Chave:}

História do futebol; Vale do São Francisco; Juazeiro;

Petrolina.

\begin{abstract}
RESUMO
A pesquisa tem como objetivo compreender os significados históricos e socioculturais de um torneio de futebol denominado BAPE - o nome designa as siglas dos estados da Bahia e Pernambuco - ocorrido nas cidades de Juazeiro-BA e Petrolina-PE. A metodologia apoia-se na Nova História Cultural, compreende publicações periódicas (da década de 1980) na imprensa escrita como fonte de pesquisa e o tratamento dos dados foi realizado pela análise documental de matérias jornalísticas que noticiaram o evento. Essas matérias refletem o quão importante foi o torneio, por ser uma iniciativa inédita que consistia em opor suas equipes de futebol amador, ritualizando sentimentos de vizinhança e rivalidade entre as cidades, compondo uma agenda esportiva e de sociabilidade para o Vale do São Francisco.
\end{abstract}

\begin{abstract}
The research aims to understand the historical and sociocultural meanings of a soccer tournament called BAPE - the name designates the acronyms of the states of Bahia and Pernambuco - occurred in the cities of Juazeiro-BA and Petrolina-PE. The methodology supports in the New Cultural History, comprises periodical publications (of the 1980s) in the written press as a source of research and the treatment of the data was done by the documentary analysis of journalistic matters that reported the event. These matters reflect how important the tournament was, as it was an unprecedented initiative to oppose their amateur soccer teams, ritualizing neighborhood feelings and rivalry between cities, composing a sports and sociability agenda for the San Francisco Valley.
\end{abstract}

\section{RESUMEN}

La investigación tiene como objetivo comprender los significados históricos y socioculturales de un torneo de fútbol denominado BAPE - las siglas designam los estados de Bahía y Pernambuco ocurrido en las ciudades de Juazeiro-BA y Petrolina-PE. La metodología apoya en la Nueva Historia Cultural, comprende publicaciones de la década de 1980 en la prensa escrita y el tratamiento de los datos fue realizado por el análisis documental de materias periodísticas que noticiaron el evento. Estas materias reflejan lo importante que fue el torneo, por ser una iniciativa inédita que consistía en oponer a sus equipos de fútbol aficionado, ritualizando sentimientos de vecindad y rivalidad entre las ciudades, componiendo una agenda deportiva y de sociabilidad para el Valle del San Francisco.

\footnotetext{
a Instituto Federal de Educação, Ciência e Tecnologia do Sertão Pernambucano, Petrolina, PE, Brasil.

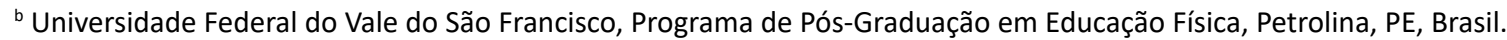

c Universidade Federal da Bahia, Programa de Pós-Graduação em Educação, Salvador, BA, Brasil.
}

\section{*Autor correspondente:}

Francisco Demetrius Luciano Caldas

E-mail: francisco.demetrius@ifsertao-pe.edu.br 


\section{INTRODUÇÃO}

O futebol, enquanto elemento da cultura e identidade nacional, cuja origem remete à Inglaterra do século XIX, disseminou-se por todo o território brasileiro, nos centros urbanos e rincões do país, se espraiando à luz de um modelo centrado nas regiões Sul e Sudeste (DIAS, 2012), com características de uma prática espetacularizada e midiática. Os lugares interioranos também passaram a o consumir e vivenciar, em suas versões mais populares e flexíveis; ganhou outras identidades, como futebol de várzea, amador ou semiprofissional.

Neste estudo, tomaremos como análise as apropriações dessa prática nas cidades vizinhas Juazeiro-BA e Petrolina-PE, situadas no Sertão Nordestino, às margens do rio São Francisco. Embora separadas pela ponte Presidente Dutra, e sem desconsiderar suas particularidades, pode-se dizer que estão unidas por relações históricas nos âmbitos econômico, político e cultural. No âmbito esportivo não é diferente. A exemplo, a partir da década de 1970, essas cidades protagonizaram um evento futebolístico denominado BAPE, cujo nome é composto pelas siglas de seus estados, Bahia e Pernambuco. Esse torneio tinha o propósito de opor suas equipes de futebol amador, movimentando o cenário futebolístico local.

O BAPE contou com a participação de diversos atores, no que se incluem as equipes ${ }^{1}$ constituídas pelos jogadores, técnicos, dirigentes, considerandose também a atuação das torcidas, dos árbitros, dos organizadores, sobretudo por meio das ligas esportivas das cidades: a Liga Desportiva Petrolinense $(L D P)^{2}$ e a Liga Desportiva Juazeirense (LDJ) ${ }^{3}$. Os admiradores do futebol, como jornalistas, empresários e membros dos poderes públicos municipais, também tiveram papel fundamental na constituição, na difusão e nos desdobramentos do evento. Suas edições estenderamse até meados da década de 1990.

Há que se destacar que a região no entorno de Petrolina e Juazeiro vivenciou, na década de 1980 , um crescimento econômico advindo das políticas nacionais de incentivo à agricultura irrigada, constituindo o polo econômico Petrolina-Juazeiro (Sobel \& Ortega, 2007). Esses esforços

\footnotetext{
1 As equipes amadoras mais consolidadas em Petrolina eram o Palmeiras, o Santa Cruz, o Náutico, o Flamengo, o Caiano, a Ferroviária, o 10 de Maio e o CEUB. Em Juazeiro, destacavam-se o Barro Vermelho, o Veneza, o Olaria, o Carranca, o XV de Setembro, o América, o Juazeiro e o Colonial. Salientamos que as primeiras equipes de futebol amador nessas cidades se organizaram a partir da década de 1920.

${ }^{2}$ A LDP foi fundada em 1948, atualmente é filiada à Federação Pernambucana de Futebol.

${ }^{3}$ Mais longeva (fundada em 1923), a LDJ é filiada à Federação Baiana de Futebol.
}

estavam centrados em infraestrutura, irrigação e incentivo ao setor privado e terminaram por projetar Petrolina nacionalmente no desenvolvimento econômico, em uma proporção consideravelmente mais acentuada do que sua vizinha Juazeiro. Essas diferenças, propulsionadas pelo desenvolvimento desigual da economia, ramificaram-se simbolicamente para a dimensão cultural, impregnando - cotidiano de seus habitantes de comparações entre as cidades, levando a rivalidades, pelas quais se questionavam qual delas possuía as melhores opções de lazer, trabalho, educação e cultura.

Do mesmo modo, as práticas esportivas, sobretudo o futebol, também se constituíram como território dessas disputas e de afirmação da supremacia de uma cidade em relação à outra. Nesse sentido, o torneio BAPE apresentou-se como um espaço no qual essas tensões se manifestaram na arena esportiva. Quem possuía o melhor futebol amador? Juazeiro ou Petrolina? Diante desse cenário, problematizamos quais os significados socioculturais da realização dessas partidas de futebol para as cidades de Juazeiro e Petrolina?

Para compreendermos esses significados, tomamos como campo de análise os conteúdos produzidos pela imprensa escrita esportiva local acerca do torneio, tendo como recorte temporal a década de 1980. O objetivo deste trabalho é interpretar os significados históricos e socioculturais associados ao torneio futebolístico BAPE na década de 1980, nas cidades de Juazeiro e Petrolina.

\section{METODOLOGIA}

Compreendemos esta pesquisa enquanto uma investigação histórica, na medida em que pretende construir um itinerário histórico e a interpretação de significados associados a partidas de futebol que opunham Petrolina e Juazeiro, metonimizadas nos times que representavam as cidades. Esta iniciativa situa-se no âmbito dos estudos históricos e socioculturais do esporte, entendidos como uma ramificação da Nova História Cultural, que procurou privilegiar a importância das investigações das práticas corporais (Burke, 2008; Melo et al., 2013).

Como fonte histórica para acessar esses significados, optamos pelo jornalismo impresso; foram acessados dois periódicos dessas cidades: o Jornal de Juazeiro e $O$ Fharol de Petrolina. Do Jornal de Juazeiro foram encontradas 55 reportagens preservadas em acervo pessoal, situado em sua sede, no centro comercial dessa cidade; esse jornal iniciou suas atividades no ano de 1972 e permanece funcionando, atualmente com o nome de Diário da Região. Do periódico O Pharol, encontrou-se duas reportagens no Museu do Sertão, na cidade de Petrolina. Esse jornal é considerado 
pioneiro na região, fundado em 1915, mantendo-se em circulação até meados da década de 1990. Não existem ações de preservação de seu acervo, com edições desorganizadas e em estado de deterioração.

As reportagens ficaram restritas aos anos de 1986, 1987, 1988 e 1989 em razão da disponibilidade das fontes que ficaram circunscritas a esse período. De um total de 57 reportagens, 48 concentraram-se no ano de 1987, uma matéria no ano de 1986, cinco no ano de 1988 e três no ano de 1989. O tratamento dos dados foi realizado por meio da análise documental, de tal modo que agrupamos as informações obtidas nas fontes em temáticas que propiciassem a facilitação da compreensão dos significados do jogo BAPE nessa década.

A pesquisa foi submetida e aprovada pelo Comitê de Ética em Pesquisa da Universidade Federal do Vale do São Francisco.

\section{O BAPE NA DÉCADA DE 1980}

As matérias jornalísticas que nos serviram de fonte nos permitem abordar variados aspectos da rotina do BAPE, tais como a rotina das equipes, as características dos jogadores, os resultados de jogos, os conflitos em campo, a atuação de dirigentes, a arbitragem e o ritual das torcidas. Iniciamos a narrativa com uma reportagem que mostra as articulações entre a LDJ e a LDP para tentar viabilizar a edição de 1988 :

Entendimentos começam a ser mantidos entre os presidentes das duas ligas no sentido de realizarem o torneio Bahia-Pernambuco este ano. Daqui ficamos torcendo para que este aconteça mesmo, pois se trata de um dos mais importantes torneios no calendário esportivo da nossa região, além de ser de grande importância para os clubes em termos de renda (BAPE ainda em 88, será? Jornal de Juazeiro, 22 a 23 de setembro de 1988, p. 8).

A matéria expõe outra intenção para a realização da competição, que era a possibilidade de, ao agregar duas forças futebolísticas, as ligas esportivas e suas respectivas equipes pudessem arejar suas situações financeiras, gerando renda a partir da presença das torcidas nos dias de jogos. Apesar de no ano de 1988 a sua edição não ter se concretizado, as prévias articulações reforçavam a dimensão econômica do evento: “[...] ambas as entidades têm interesse na realização do BAPE, porque na verdade essa competição é o que pode existir de mais rentável no futebol regional" (Será que vai mesmo haver o BAPE? Jornal de Juazeiro, Juazeiro, 27 a 29 de Fevereiro de 1988, p. 8).

As reuniões entre as ligas eram espaços inclinados à democracia de ideias e sugestões. Esta matéria relatou que:
Após a realização da reunião feita pela LDP em sua sede na cidade de Petrolina, ficou tudo acertado quanto ao regulamento da disputa. Nessa reunião tivemos a presença de todos os 16 clubes que irão participar do torneio, e dos presidentes da LDJ e LDP (Definido o regulamento do torneio Bahia e Pernambuco. Jornal de Juazeiro, 28 e 29 de janeiro de 1987, p. 8).

Essas ligas eram, por excelência, espaços comunitários construídos e reconhecidos por esses atores. Os estudos de Myskiw e Stigger (2014) apresentam dois modelos para compreendermos essas organizações internas do futebol. O primeiro inclina-se para o futebol profissional, denominado "mais próximo do profissional" e o segundo mais distante é chamado de "aqui é a várzea". No período investigado, as ligas do BAPE se aproximavam mais do segundo modelo. Ainda que tivessem características que, como demonstraremos, permitiam alguma identificação com o espectro esportivo profissional - tais como a regulação de contratos em diferentes âmbitos, a condição e importância dada aos árbitros, a identidade dos torcedores e a presença feminina em um esporte masculino (em um local e em um tempo culturalmente conservadores) - as identificações com o futebol de várzea eram predominantes.

Também foi possível identificar que nem sempre era possível manter relações saudáveis entre as mentoras do evento, a LDJ e a LDP. Devido ao rompimento de um acordo que regulamentava a contratação de jogadores para o torneio, os organizadores do futebol de Juazeiro romperam publicamente com o futebol de Petrolina, não havendo a edição do ano de 1989.

Essa discordância projetou uma reportagem, que provavelmente esclareceu o motivo da ausência dessas partidas no jornal nesse ano.

Em virtude dos últimos acontecimentos, com a saída de vários jogadores de Juazeiro para Petrolina, com o futebol da vizinha cidade mais uma vez desrespeitando acordo feito com diretores de Juazeiro, na reunião de segunda-feira passada, os dirigentes de Juazeiro tomaram uma decisão unânime de cortar definitivamente os laços de amizade e cooperação que havia entre as duas ligas e que infelizmente nunca foi respeitado pelos nossos colegas da vizinha cidade. Um documento foi elaborado e vai ser enviado para divulgação em todos os setores esportivos do grande vale. Neste documento o ponto principal em questão é a punição que cada atleta de Juazeiro levará caso venha a atuar em Petrolina depois de ter assinado com os clubes de Juazeiro e devidamente iniciado o campeonato [...]. Com estas determinações fica definitivamente descartada a possibilidade de um BAPE (Torneio Bahia-Pernambuco) pelo menos entre 
Juazeiro e Petrolina (Futebol de Juazeiro corta laços com o de Petrolina. Jornal de Juazeiro, 16 de março de 1989, p. 8).

Entre as advertências desse documento, chamado de Carta aberta aos desportistas de Juazeiro e região, um tópico é direcionado ao BAPE. Ele enfatiza que "[...] a partir desta data e enquanto perdurar o rompimento, fica suspenso o Torneio Bahia-Pernambuco (BAPE) e qualquer amistoso envolvendo equipes Juazeirenses contra as Petrolinenses em qualquer das duas praças esportivas e ou em campo neutro" (Carta aberta aos desportistas de Juazeiro e região. Jornal de Juazeiro, 17 de março de 1989, p.7). A normativa se intensificava nos arautos finais:

Atletas ficam penalizados por três anos e seus passos presos a LDJ, além desta medida extrema, dentro da lei, seus nomes estarão em uma LISTA NEGRA, que será oportunamente divulgada como castigo por sua inconstância e desamor a prática esportiva (Carta aberta aos desportistas de Juazeiro e região. Jornal de Juazeiro, 17 de março de 1989, p. 7).

Essa medida punitiva era contra a atitude de mudar de equipe ignorando as normas; aquele que o fizesse estaria praticando um ato de desamor a seu município. $A$ adesão de um jogador a uma equipe de uma das cidades não estava condicionada à sua naturalidade, jogador natural de Petrolina podia atuar em uma equipe de Juazeiro e também o contrário. No entanto, um jogador não poderia mudar de agremiação se estivesse comprometido com uma equipe no momento em que o torneio já estivesse iniciado. Devido ao maior poderio econômico de Petrolina, essas tensões se potencializavam em meio às contratações. Inferimos que a não realização da competição nesse ano (de 1989) acarretou impactos socioculturais negativos para o torneio, tais como a perda de prioridade na agenda esportiva das duas cidades. No ano seguinte nenhuma matéria foi identificada nos jornais sinalizando a presença do BAPE nos gramados locais.

A respeito da dinâmica da competição, suas articulações ocorriam geralmente nos meses de janeiro e fevereiro, começando as partidas de imediato. Essa dinâmica estava sujeita a certas variáveis, entre elas a programação dos estádios com eventos culturais, o andamento dos campeonatos municipais, o apoio financeiro municipal e empresarial, a resolução das demandas de infraestrutura e até a agilidade no consenso das propostas de tabelas de jogos e regulamento. $\mathrm{Na}$ tentativa da sua edição de 1988, que não se concretizou, encontramos: "[...] o torneio que foi idealizado no primeiro semestre, este ano deverá ocorrer no segundo em virtude do grande atraso no campeonato municipal de 87 , que ninguém sabe quando será concluído" (Será que vai mesmo haver o BAPE? Jornal de Juazeiro, 27 a 29 de fevereiro de 1988, p.6).

As matérias que abordaram a forma de disputa foram abundantes. Pregaram que, pelo regulamento, o torneio era constituído por dois grupos, o primeiro composto por equipes que obtiveram os melhores resultados no campeonato local do ano anterior ${ }^{4}$, e o segundo grupo pelo restante dos outros clubes. Os jogos aconteciam aos sábados e domingos, ambos em rodada dupla. Petrolina e Juazeiro entravam na disputa com o número igual de equipes, que correspondia a oito.

Definidos os grupos, o primeiro e o segundo colocados do primeiro grupo e o primeiro e segundo colocados do segundo grupo fariam um confronto direto de caráter eliminatório. Os dois vencedores do quadrangular decidiriam a final do torneio em duas partidas, sendo a segunda e decisiva partida realizada no campo da equipe com a melhor campanha ao longo do torneio. Os dois finalistas eram necessariamente uma agremiação de Petrolina e uma de Juazeiro. Essas partidas se realizavam nos Estádios Adauto Morais de Juazeiro e Associação Rural de Petrolina.

Essa dinâmica de troca de estádio reforçava os mecanismos de sociabilidade no jogo, oferecendo oportunidades de criar ou reforçar laços de amizade e aliança. A ação de receber a equipe de outra cidade ou mesmo de visitar o campo do adversário implica regras e deveres inteligíveis dentro de uma lógica de reciprocidade (Spaggiari, 2008).

Os Dirigentes esportivos também ganharam as páginas jornalísticas. Uma reportagem relatou que o “[...] presidente Jackson Figueiredo está jogando alto no time caianense, para colocar a melhor equipe, no momento, de Petrolina, e como a mais favorita" (Times de Juazeiro prontos para a estreia no BAPE. Jornal de Juazeiro, 03 a 04 de fevereiro de 1987, p. 8).

Sobre os técnicos, destacou-se o treinador Baé da agremiação juazeirense Veneza, o Jair Garrido do time petrolinense Caiano, o Dino da equipe Barro Vermelho de Juazeiro e o Raimundo Amarildo da equipe Juazeiro. Eram percebidos em diferentes frentes, nas alterações em jogo ou na expectativa de indicação ao cargo: "[...] com um placar que não lhe era favorável, o técnico Baé, do Veneza, arriscou mais uma chance substituindo o lateral Geré, pelo meio-campista Adilson que mesmo improvisado deu conta do recado" (José Geraldo. Agora está mais difícil, Veneza. Jornal de Juazeiro, 12 a 13 de maio de 1987, p. 8).

\footnotetext{
${ }^{4} \mathrm{O}$ campeonato de futebol de Juazeiro, denominado Juazeirense; $\mathrm{e}$ o de Petrolina, o Petrolinense.
} 
Em um futebol comunitário que tentava reproduzir características profissionais, os jogadores ganhavam força nas representações características de um ídolo esportivo. Mas esses jogadores, em sua maioria, depois das partidas retornavam para seus cotidianos, como qualquer outro participante do jogo, dada a escassez de relações mais profissionais. $O$ retorno financeiro existia quando aconteciam os jogos ou uma temporada. $\mathrm{Na}$ ausência de competições, o sustento vinha além das quatro linhas, corroborando as considerações de Rigo, Jahnecka e Silva (2010), que afirmam que a maioria das pessoas que disputam esse tipo de competição são jogadores-trabalhadores oriundos de classes mais populares e o fazem por um misto de lazer e trabalho.

Na construção desses "ídolos-heróis", a imprensa funcionava como um instrumento de consolidação de uma carreira futebolística que estava à espreita de uma oportunidade para migrar das equipes locais para os clubes das capitais. Entre os jogadores que ganharam popularidade nas partidas do BAPE, a edição de 1987 concedeu espaço a um deles: "O ex-artilheiro do Veneza Fumachú, que agora vestirá a camisa tricolor do Barro Vermelho está mais que confiante numa boa vitória frente ao time do Palmeiras" (Fumachu confiante em sua estreia no Bahia e Pernambuco. Jornal de Juazeiro, 07 a 08 de fevereiro de 1987, p. 8).

Da rotina dos jogadores, a imprensa destacava o período de articulação para a composição das equipes. Uma verdadeira corrida contra o tempo entre dirigentes e treinadores. Como os contratos de curto ou longo prazo eram instáveis, a lei da oferta e procura se instalava.

É grande a caça a jogadores e a lei da oferta está valendo mais. Nas ruas o comentário é grande e as expectativas ficam mais fortes para a dança das contratações. Muita coisa ainda vai rolar e grandes surpresas virão à tona dentro desse círculo de quem vai contratar mais. E aqui em nossa cidade os clubes filiados à LDJ não param de contratar, fazendo uma rivalidade forte entre os clubes de Juazeiro e Petrolina (José Geraldo. Times motivados pra o Bahia-Pernambuco. Jornal de Juazeiro, 10 de janeiro de 1987, p. 5).

As ligas gerenciavam outros eventos esportivos da época e nessa edição de 1987 acessamos as relações do BAPE com outros certames, como os campeonatos municipais. As deliberações para a contratação de jogadores nessa edição geraram polêmicas:

Mas o detalhe que chamou mais atenção nesta reunião foi justamente a respeito do artigo que fala da contratação de um atleta por qualquer clube. 0 artigo diz que o atleta que for inscrito por qualquer agremiação das duas divisões do BA-PE estará preso também nas disputas dos dois campeonatos municipais, não podendo transferir-se para outra agremiação que tiver interesse em seu passe, pois poderá ser eliminado da competição (José Geraldo. Definido regulamento do torneio Bahia e Pernambuco. Jornal de Juazeiro, 28 a 29 de janeiro de 1987, p. 8).

Outros atores que ganharam as páginas dos periódicos foram os árbitros. A carreira dos árbitros advinha de outras experiências desse universo futebolístico. $\mathrm{O}$ acúmulo de outros capitais corporais como de ex-jogador, ex-técnico ou dirigente, alicerçava os saberes necessários para legitimar sua atuação.

A função de aplicar regras a favor ou contra uma equipe pode gerar situações de estresse e pressão em cima desses atores dentro e fora do campo. No BAPE não foi diferente: "[...] depois de tantos desabafos e desaforos, os três membros do quadro de árbitros, presentes na reunião, afirmaram que se até hoje à noite nada for definido, ninguém vai apitar nos jogos da sexta-feira, sábado e domingo" (Alencar. Tiro Livre. O Pharol, Petrolina, 28 de fevereiro de 1987, p. 8).

Nessas fontes, as torcidas representaram processos de identidade com um determinado time ou clube. Buarque de Hollanda e Melo (2012) refletem a respeito do ethos do torcedor, afirmando que o primeiro olhar da sociedade para as torcidas de futebol compreende esse torcedor como um indivíduo de comportamento irracional, que se vale do esporte como uma forma de evasão das vicissitudes do cotidiano, ou como um fluxo do excesso de emoções.

Os estudos de Souza Neto (2012) sinalizam transformações importantes no que hoje chamamos de torcida ou torcedores. Assinala que entre os anos de 1904 e 1910 o público futebolístico estava muito mais voltado para uma prática social do que propriamente para um posicionamento a favor de um determinado clube; a intenção era tornar o jogo uma vivência social. Entre 1910 e 1915 encontramos as primeiras referências de públicos concorrendo às partidas. 0 futebol começa a fomentar sentimentos de rivalidade e, quando chegamos ao período de 1916 a 1925, um jeito novo de estar nos campos é vivenciado, inclusive com a invenção da palavra torcedor (Souza Neto, 2012). Toledo (2002) pontua que os anos de 1940 e 1950 demarcam na sociabilidade esportiva maior aceitação dos torcedores pela sociedade, sobretudo a respeito das formas coletivizadas de torcer.

Em Petrolina e Juazeiro as torcidas chamaram a atenção da imprensa local, e raramente uma matéria não trazia alguma alusão às suas manifestações. Entre muitos personagens, os jornais destacaram uma representação do time do Veneza, a "Dona Dalva". Assim diziam: 
Com muita fé, acreditando na ajuda do Deus supremo, a torcedora pé quente e número 1 do Veneza Dona Dalva está articulando com outros adeptos da nação azulina uma vasta programação no sentido de colorir ainda mais o Adauto Morais no jogo deste domingo de seu time contra o Caiano de Petrolina (Veneza e a volta por cima. Jornal de Juazeiro, 14 a 15 de maio de 1987. p. 6).

Nessa edição de1987, entre matérias queabordaram frustações com equipes expressas em vaias calorosas, torcidas exclusivamente femininas da agremiação Barro Vermelho ou arquibancadas inflamadas pelos jogadores do time do Veneza, destacamos iniciativas que atestavam o compromisso afetuoso dessas torcidas com seus times. Não bastava vibrar com as jogadas, era preciso se organizar coletivamente: “[...] para isso a torcida organizada do clube colocou à venda carnês, para que os torcedores possam ajudar o clube com a mensalidade de $\mathrm{Cz} \$ 100.00$. Esta quantia servirá para pagar os jogadores nesta temporada" (Times de Juazeiro prontos para a estreia no BAPE. Jornal de Juazeiro, 03 a 04 de fevereiro de 1987, p. 8).

Outras notícias se ocuparam da ansiedade de torcedores por um novo escrete, das movimentações de ocupação nos campos como forma de intimidar o oponente, e o clima de "guerrilha" e festa que tomavam conta dos domingos de clássicos.

A torcida já vive as expectativas de não só ver a estreia do Barro no Bahia Pernambuco, mas a de ver o crioulo Fumachú. De bronca ainda fica a torcida do Veneza, que perdeu seu craque (Fumachu confiante em sua estreia no Bahia e Pernambuco. Jornal de Juazeiro, 07 a 08 de fevereiro de 1987, p. 8).

A imprensa esportiva Petrolinense anuncia que a torcida caianense promete invadir o estádio Adauto Morais e superar a torcida do Veneza. Para isso os chefes da torcida organizada do Caiano já estão mobilizados (Veneza e Caiano, a grande atração no Adauto Morais. Jornal de Juazeiro, 07 a 09 de março de 1987, p. 6).

Compreender essas torcidas e seus rituais é também acessar os sentimentos desses sujeitos com seus times, ou seja, seu pertencimento clubístico. Essas cidades, por situarem-se distantes dos grandes centros urbanos, e pela predominância midiática do futebol no Sudeste do país, eram, e ainda são, influenciadas pelas agremiações profissionais dessa região do país. Esse fato sustenta a condição de muitos torcedores possuírem mais de um time do "coração" nessa região nordestina. Vasconcelos (2011) trata-os como "torcedores mistos", percebidos muitas vezes de forma pejorativa, como uma legião de aculturados pela mídia sulista.

Petrolina e Juazeiro não fogem dessa realidade, mas nem por isso os clubes locais foram preteridos. Ao contrário, foram exaltados nas partidas do BAPE. Nesse espaço, avolumavam-se relações de amizade e inimizade, de provocação e brincadeiras entre as torcidas, que poderiam ser pensadas como pares de oposições (Buarque de Hollanda \& Melo, 2012).

\section{AS TORCIDAS E OS RITUAIS DE RIVALIDADE}

É possível refletir as rivalidades no BAPE a partir de duas perspectivas. A primeira diz respeito à própria essência do jogo e a segunda ao contexto sociocultural em que essas partidas aconteciam. Iniciamos com a compreensão de Damo (2001), ao tratar o jogo de futebol enquanto um ritual disjuntivo. Nesse sentido, uma partida de futebol é regida pela lógica de que ao seu término, uma equipe sairá vencedora e a outra perdedora. Amparado pelo olhar antropológico, Damo (2001) realiza uma analogia entre essas formas de disputas modernas ou ocidentais com as primitivas. Nas disputas modernas, o início é marcado pela equivalência entre as partes, "para, ao final, produzirse a assimetria, uma disjunção entre vencedores e vencidos" (Damo, 2001, p. 4). Nas formas primitivas, as partes estão inicialmente em desequilíbrio, entre iniciados e não iniciados, por exemplo, e ao fim são integradas sob uma mesma categoria. Dessa forma, o primeiro caso provoca uma assimetria pelos acontecimentos do jogo, enquanto que no segundo a simetria é pré-ordenada na própria organização do jogo. É essa imprevisibilidade que vem da disjunção que estimula a sensibilidade daqueles envolvidos numa partida de futebol, uma excitação que provoca tensões nos jogadores e nas torcidas.

No BAPE, os jogos entre equipes de Petrolina e Juazeiro se davam por forças oponentes, um tipo de simulacro de "guerra". Os esportistas protagonizam situações de tensão ou mesmo violência.

Os torneios Pedro Lajú e Bahia-Pernambuco foram promovidos este ano com o simples propósito de "unir" o futebol de Juazeiro e Petrolina no que viria a ser chamado mais tarde de confraternização futebolística. Pelo menos, foi o que tentaram pregar os presidentes José Carlos Tanuri e Vinícios de Santana da LDJ e LDP, respectivamente. Contudo este ensinamento ficou distante de ser seguido mais uma vez com os fatos registrados no domingo passado no estádio da Associação Rural quando da partida envolvendo os selecionados das duas cidades. [...] Este jogo que encerrou o ciclo de encontros das duas cidades no futebol, deveria ter uma outra conotação 
e quem sabe até um outro comportamento (José Geraldo. Bahia - Pernambuco serviu mesmo de união para Juazeiro e Petrolina? Jornal de Juazeiro, 24 a 26 de junho de 1987, p. 9).

Mas atletas de Petrolina, não atingindo a todos, sempre chegados a uma confusão tiverem que novamente dar um espetáculo negativo provocando o maior sururu em campo. Quem não se recorda do zagueiro Fernando, do Palmeiras, que na decisão do primeiro turno do BAPE contra o Barro Vermelho, ao ser expulso teria se armado com uma faca e provocando o maior badauê no Adauto Morais. Pois é torcedor, novamente Fernando domingo passado defendendo a seleção de Petrolina, tirou uma de Maguila, grande representante dos pesos pesados no Brasil e atingiu o árbitro da LDJ, José Francisco Barbosa (José Geraldo. Bahia - Pernambuco serviu mesmo de união para Juazeiro e Petrolina? Jornal de Juazeiro, 24 a 26 de junho de 1987, p. 9).

A segunda perspectiva apontada para entendermos os significados dessas rivalidades é o contexto social e cultural dessas cidades. Como dissemos, Petrolina e Juazeiro cresceram economicamente nas proximidades do rio São Francisco, formando o maior aglomerado urbano do semiárido brasileiro. Por mais que comungassem de bens de serviço e consumo, centrados na agricultura e fruticultura, essas cidades trilharam caminhos díspares nas suas questões macroeconômicas. Petrolina alçou uma condição superior no desenvolvimento econômico em relação a Juazeiro. Nesse cenário, as discussões em torno das identidades e diferenças ganharam fôlego nos rituais das disputas. Essas tensões, provenientes da dinâmica cultural, se potencializaram no campo esportivo, na hora do jogo, no comportamento das torcidas, de tal modo que torcer por um time de Petrolina ou Juazeiro também passou a significar a exaltação de uma cidade sobre a outra. Como sinalizam os estudos de Norton (1997), a identidade é construída socioculturalmente em suas relações com as mudanças sociais e as relações econômicas, numa perspectiva de "investimento".

\section{CONSIDERAÇÕES FINAIS}

O volume considerável de matérias sobre o torneio na década de 1980 demonstra a presença dos jornais em ações comunitárias de cunho esportivo na região, sobretudo no futebol. O BAPE tornou-se, por essas lentes, um elemento de análise sobre as possibilidades e limites de relações afetuosas entre as duas cidades. As matérias o retrataram como um evento de popularidade no cenário esportivo local; e como uma ação cultural e esportiva consolidada no imaginário futebolístico de Petrolina e Juazeiro.
A matéria intitulada Bahia-Pernambuco serviu mesmo de união para Juazeiro e Petrolina?, anteriormente mencionada, nos possibilita acessar o impacto cultural da competição nas relações entre as duas cidades. Seu título reforça a existência de tensões ou rivalidades entre as cidades, advindas, em alguma medida, do contexto econômico desigual, e que o BAPE seria uma possibilidade no campo esportivo para que o clima competitivo entre ambas fosse dirimido. Todavia, com o desenrolar do campeonato, percebese que, pelo menos na década de 1980, o BAPE não arrefeçou essas tensões; ou seja, não serviu para unir Petrolina e Juazeiro. Ao contrário, provocou uma cisma entre suas entidades esportivas e, consequentemente, no futebol amador do Vale do São Francisco.

Se levarmos em conta que esse contexto também foi permeado pelo congraçamento entre essas cidades, sinaliza-se a presença de um paradoxo. 0 olhar da imprensa escrita demarcava tensões que contribuíam, aparentemente, mais para distinguir do que para associar essas duas cidades, contrariando a própria essência do BAPE; que era unir e potencializar o futebol de Juazeiro e Petrolina a partir de um futebol caracterizado como comunitário, por mais que flertasse com o futebol espetáculo (Damo, 2007).

Os desarranjos em seu gerenciamento, somados à concorrência com outros eventos, tornaram-se influências significativas para suas próximas edições na década de 1990, culminando com sua interrupção no ano de 1996. Nesse sentido, evidenciamos a singularidade do BAPE no Vale do São Francisco na década de 1980 como um evento cujo significativo consumo cultural e a proveniente força simbólica denotam a força do futebol amador no Sertão Nordestino, tornando-se um espaço de convivência, tensões, emoções e de afirmação de identidades.

\section{REFERÊNCIAS}

Buarque de Hollanda, B; Melo, VA (orgs.). O esporte na imprensa e a imprensa esportiva no Brasil. Rio de Janeiro: 7 Letras, 2012.

Burke, P. O que é história cultural? Rio de Janeiro: Jorge Zahar, 2008. Damo, AS. Futebol e estética. São Paulo em Perspectiva, v. 15, n. 3, p. 82-91, jul./set. 2001.

Damo, AS. Do dom à profissão: formação de futebolistas no Brasil e na França. São Paulo: Hucitec: Anpocs, 2007.

Dias, C. História do esporte no Sertão Brasileiro: memória, poder e esquecimento. Materiales para la Historia del Deporte, n. 10, p. 24-36, 2012.

Melo VA; Drumond, M; Fortes, R; Santos, JM. Pesquisa histórica e história do esporte. Rio de Janeiro: 7 letras, 2013.

Myskiw, M; Stigger, MP. Lazer e identidades: retratos etnográficos num circuito de futebol. Revista Brasileira de Estudos do Lazer, Belo Horizonte, v. 1, n. 1, p.68-84, jan./abr. 2014.

Norton, B. Language, identity, and the ownership of English. TESOL Quarterly, v. 31, n. 3, p. 409-429, 1997. 
Rigo, L; Jahnecka, L; Silva, I. Notas etnográficas sobre o futebol de várzea. Movimento, v. 16, n. 3, p.155-179, 2010.

Sobel, TF; Ortega, AC. Estratégias de desenvolvimento territorial: o caso do polo Petrolina-Juazeiro. Anais do XLV Congresso da Sociedade Brasileira de Economia, Administração e Sociologia Rural, 2007.

Souza Neto, GJ. A invenção do torcer em Belo Horizonte: da assistência ao pertencimento clubístico (1904 - 1930). In: Silva, SR; Debortoli, JAO; Silva, TF. (orgs.). O futebol nas gerais. Belo Horizonte: Editora UFMG, 2012.
Spaggiari, E. Ganhar jogo, pagar jogo e ganhar visita: prática futebolística em um bairro rural. Horizontes Antropológicos, Porto Alegre, ano 14, n. 30, p. 165-190, jul./dez. 2008.

Toledo, LH. Lógicas do futebol. São Paulo: Hucitec, 2002.

Vasconcelos, AA. Identidade futebolística: os torcedores "mistos" no Nordeste. Dissertação de mestrado. Universidade Federal do Ceará. Departamento de ciências sociais, 2011. 